\title{
Shear impact during steel wire drawing on grain boundaries and mechanical properties
}

\author{
A. Zavdoveev ${ }^{\dagger, 1}$, T. Baudin 2 , M. Rogante ${ }^{3}$, E. Pashinska ${ }^{4}$, M. Skoryk ${ }^{5}$ \\ †avzavdoveev@gmail.com \\ ${ }^{1}$ Paton Electric Welding Institute of NAS of Ukraine, 11 Bozhenko, Kiev, 03680, Ukraine \\ ${ }^{2}$ Université Paris-Saclay, CNRS, Institut de chimie moléculaire et des matériaux d’Orsay, Orsay, 91405, France \\ ${ }^{3}$ Rogante Engineering Office, Contrada San Michele n. 61, Civitanova Marche, 62012, Italy \\ ${ }^{4}$ A. A. Galkin Donetsk Institute for Physics and Engineering of NAS of Ukraine, 46 pr. Nauky, Kyiv, 03028, Ukraine \\ ${ }^{5} \mathrm{G}$. V. Kurdyumov Institute of Metal Physics of the NAS of Ukraine, 36 Ac. Vernadsky, Kyiv, 03142, Ukraine
}

Shear deformation is one of the effective ways for grain boundary engineering. In the current contribution, the effect of the shear deformation incorporated into the conventional drawing process is shown. A specific feature of this experimental technology is a reduction of the structural anisotropy. This effect is related to the application of dies with shear that makes the metal flow to change its direction. In particular the grain refinement is stronger. The experimental drawing technology results in an extensive increase in the fraction of small grains (less than $3 \mu \mathrm{m}$ in size) and a decrease in the fraction of large grains. A large amount of small grains with high-angle boundaries in this case is registered. The formation of this kind of grains is explained by progress in competing processes of large grain fragmentation and continuous dynamic recrystallization. The result is the change of the type of the grain boundaries from smooth to serrated ones and the formation of unclosed high-angle grain boundaries. Besides, it has been demonstrated that a certain part of small grains provides grain boundary sliding. The comparative analysis of the hardness tests has demonstrated increasing hardness with deformation accumulation, but after the classical drawing, the hardness grows linearly and stepwise after the experimental shear drawing. The physical reasons of such behaviour are explained by microstructural features which are discussed in current contribution.

Keywords: shear deformation, structure, properties, grain boundary, grain refinement, low-carbon steel.

\section{Introduction}

It is commonly known that the relationship between the structure and properties of metals is the main goal of material science [1-4]. In particular, there are several mechanisms which determine the strength of steel: dislocation, solid solution, dispersion precipitation, and grain boundary strengthening. The latter mechanism provides the most valuable effect on the strength of material: up to $40 \%$ of overall hardening input is due to the grain refinement [5]. Therefore, controlling the characteristics of grain boundaries (GB), mechanical properties of materials can be changed [6-10]. Shear deformation is one of effective ways of GB engineering. In the present work, a successful attempt was developed to incorporate shear deformation into the conventional drawing process [11-13]. There is currently a significant commercial interest in the development of materials using GB engineering methods $[10,14,15]$. An additional reason for the interest is the concept that control of the mechanical properties by processing may be more attractive than the current practice of controlling them by alloying. This would result in the use of fewer and simpler industrial alloys and would lead to economic benefit as well as improved recyclability. Techniques for the production of the fine-grained alloys are thus of considerable scientific and commercial interest. Of particular importance in this context are cost-effective approaches that can be used to produce large quantities of such materials. A combination of severe plastic deformation (shear deformation) with conventional deformation processes appears to have great potential in this area. In this study, the feasibility of a new technology of drawing with shear for commercial wire production is evaluated. The process of drawing with shear is virtually a derivative of known twist extrusion technique [16-18], which was adapted for the wire-drawing. It was believed that the grain-refinement effect associated with the shear deformation enables one to increase the material strength and thus to improve the service properties of the product. Additionally, the specific "twist" character of material flow during this process was suggested to suppress cracking and thus enable avoiding intermediate annealing steps. To evaluate the feasibility of this new GB engineering approach, its effect on the strength of the material and its structure in terms of the grain size and nature of grain boundaries were examined and compared with that of conventional wiredrawing. 


\section{Methodology}

A billet of a low-carbon steel the characteristics of which are presented in Table 1 was used for studies. The condition of the billet was as received from a metallurgical plant (hot rolled rod $6.15 \mathrm{~mm}$ in diameter). The drawing was carried out at the AZTM 7000/1 drawbench at ambient temperature using the experimental procedure of dies to provide a twist flow of the metal during the drawing process and by the classical technology using the standard round dies. The drawing routes for both technologies are presented in Table 2 .

The microstructure of the annealed and deformed samples was studied at a magnification of $100-2000$ by a «Neophot-32» microscope after multiple polishing and etching of grain boundaries (the composition of the etching agent was $4 \%$ of nitric acid, $96 \%$ ethylene). The photos were made by an Axiovert 40 MAT optical microscope. The quantitative estimation of the grain size and its fragments was made in both transversal and longitudinal directions. 100 measurements were made on every photo. The aspect ratio was calculated by the relation

$$
k=D 1 / D 2 \text {, }
$$

where $D 1, D 2(\mu \mathrm{m})$ are the transversal and longitudinal sizes of a grain, respectively.

The closer $k$ is to 1 , the higher isotropy of the tested structure is registered.

The obtained samples ranging from 6.15 to $1.55 \mathrm{~mm}$ in diameter were measured for such physical properties as hardness and density. Vickers HV hardness was measured at the loading of $200 \mathrm{~g}$. The statistical error of the measurement did not exceed $5 \%$. The density was measured by hydrostatic weighing by using the weighing scales AX-200 by Shimadzu.

The microstructure of the samples was also characterized using a scanning electron microscope JSM-6490LV by the method of electron backscatter diffraction (EBSD-analysis). Samples with a diameter of 5.0 and $3.9 \mathrm{~mm}$ were scanned with a step of $0.5 \mu \mathrm{m}$ at the magnification of 500 and with a step of $0.3 \mu \mathrm{m}$ at a magnification of 1000 . The samples were prepared by a standard approach. Electrolytic polishing was carried out in the electrolyte solution of the following composition (wt.\%): $65 \%$ ortophosphoric acid, 15\% sulphuric acid, $6 \%$ chromic anhydride and $14 \%$ water [19]. The operating conditions were the as follows: working temperature $70-90^{\circ} \mathrm{C}$, anodic current density $1 \mathrm{~A} / \mathrm{cm}^{2}$, voltage $23 \mathrm{~V}$ and exposure $19 \mathrm{~s}$. The electrolyte was cooled by flowing water.

\section{Results and discussion}

\subsection{Optical microscopy}

One of the specific features of the experimental technology is a reduction of the structure anisotropy. Compared with the "experimental" samples in the longitudinal section, the anisotropy is expressed more in the "classical" samples, ferrite grains are smaller, the perlite colonies are stretched in stripes. The perlite colonies in the "experimental" samples are less elongated, but more rounded (Fig. 1). The same effect is observed in the cross-section. This fact is confirmed by the data on the aspect ratio with an increase in the strain, i. e. reduction in diameter (Table 3).

The classical drawing technology is associated with a decrease in the aspect ratio when the diameter of the samples is reduced. The reason is that drawing is a kind of uniaxial deformation. In the course of the processing, the grains are oriented and stretched along the deformation axis, with a consequent decrease in the width. That is why the aspect ratio has been gradually reduced from 0.65 to 0.12 for the classical drawing.

A certain non-linear decrease in the aspect ratio is also observed after the experimental technology. However, the increase up to 0.72 characterizes the sample $\varnothing 3.9$ compared with 0.47 for the $\varnothing 5.0$. This effect is related to the application of a die with shear that forces a change in the path of metal flow.

The analysis by optical microscopy results allowed fixing the following principal structure features.

When drawing by the classical technology, an increase of strain is associated with the reduction of grain size according to the Polani-Taylor principle [20] (Table 4). It has been established that the classical technology results in an increase in the grain size in the longitudinal section and its reduction in the cross-section. Contrary to the classical drawing, the modification of the grain size in the course of the experimental shear drawing is non-monotonic and has a cyclic character with an alternative decrease and increase of the grains size. In the longitudinal section, the experimental technology results

Table 3. Aspect ratio $k$ for the low-carbon steel wire.

\begin{tabular}{|c|c|c|c|c|}
\hline \multirow{2}{*}{ Technology } & \multicolumn{4}{|c|}{$k$} \\
\cline { 2 - 5 } & $\varnothing 6.15$ & $\varnothing 5.0$ & $\varnothing 3.9$ & $\varnothing 1.55 / \varnothing 1.88$ \\
\hline Experimental & \multirow{2}{*}{1} & 0.47 & 0.72 & 0.28 \\
\cline { 1 - 3 } Classical & & 0.65 & 0.44 & 0.12 \\
\hline
\end{tabular}

Table 1. Chemical composition of the wire of the low-carbon steel, wt.\%.

\begin{tabular}{|c|c|c|c|c|c|c|c|c|}
\hline $\mathrm{C}$ & $\mathrm{Mn}$ & $\mathrm{Si}$ & $\mathrm{S}$ & $\mathrm{P}$ & $\mathrm{Cr}$ & $\mathrm{Ni}$ & $\mathrm{Cu}$ & $\mathrm{N}$ \\
\hline 0.071 & 1.98 & 0.84 & 0.015 & 0.018 & 0.015 & 0.009 & 0.016 & 0.0055 \\
\hline
\end{tabular}

Table 2. Drawing routes of the wire produced by the experimental and classical technologies.

\begin{tabular}{|c|c|}
\hline Technology & Die diameter, $\mathrm{mm}$ \\
\hline Experimental & $\varnothing 6.15 \rightarrow \varnothing 5.45^{\star} \rightarrow \varnothing 5.0 \rightarrow \varnothing 4.7^{\star} \rightarrow \varnothing 4.20 \rightarrow \varnothing 3.9 \rightarrow \ldots \rightarrow \varnothing 1.55$ \\
\hline Classical & $\varnothing 6.15 \rightarrow \varnothing 5.45 \rightarrow \varnothing 5.0 \rightarrow \varnothing 4.40 \rightarrow \varnothing 3.9 \rightarrow \ldots \rightarrow \varnothing 1.88$ \\
\hline
\end{tabular}

*a die with shear (providing twist flow of the metal) 

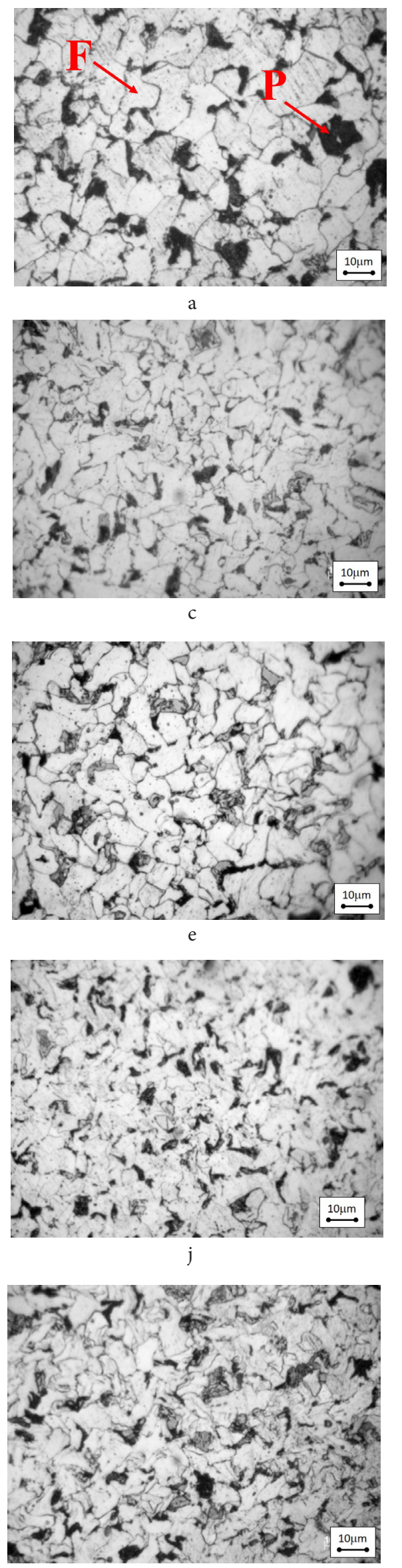
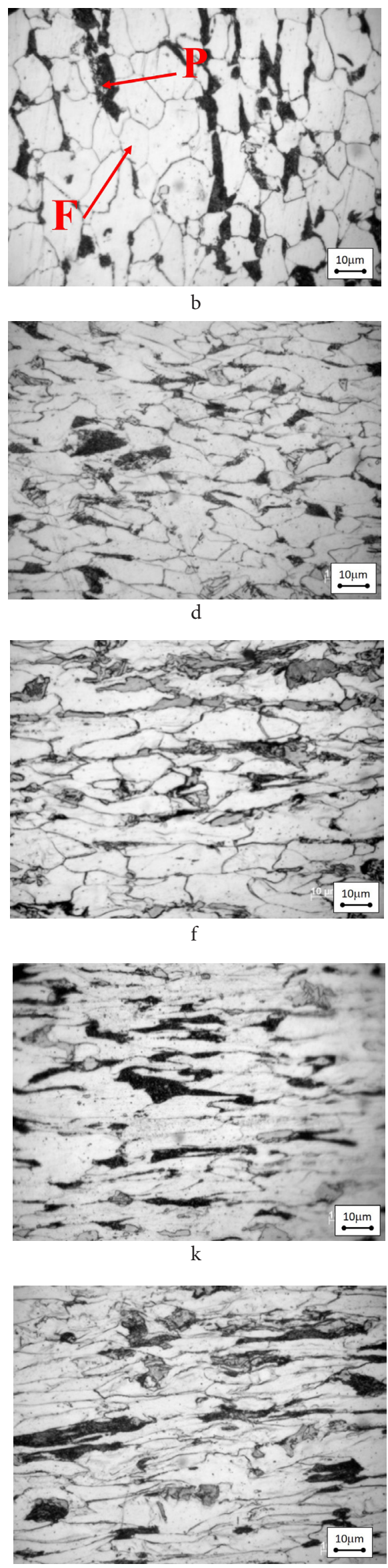

$\mathrm{m}$

Fig. 1. Microstructure of low-carbon steel wire after drawing: initial as received state (a,b), Ø6.15; classical technology (c, d, j, k); experimental technology (e, f, l, m); Ø5.0 (c, d, e, f); Ø3.9 (j, k, l, m); cross section (a, c, e, j, l), longitudinal section (b, d, f, k, m); magnification $-\times 1000$. 
in a decrease of the grain size (from 9.02 to $4.53 \mu \mathrm{m}$ ). This effect can be explained by both the changes in the path of metal flow within the dies with shear and a possible progress in the competing processes of fragmentation and dynamic polygonization/recrystallization.

The question can be solved using structure analysis by a scanning electron microscope (i.e. EBSD). The data of the EBSD analysis listed below will detail the concept of the structure formation.

The curves illustrating the grain size distribution are presented in the section along the drawing axis Fig. $2 \mathrm{a}$, b. It is well seen that the experimental drawing technology results in a substantial increase of the fraction of small grains and a decrease in the fraction of coarse grains. For instance, if the classical drawing technology is applied, the presence of the grains larger than $44 \mu \mathrm{m}$ is registered (Fig. 2). After the experimental drawing, the grains larger than $32 \mu \mathrm{m}$ (Fig. 2) are not observed.

The data on the size distribution of the grains in the section across the drawing axis are shown in Fig. 2 c, d. The size distributions are very similar at the initial stages of deformation. As the strain increases, the grains of the sample subjected to the experimental drawing become two times smaller than the grains after the classical drawing. Besides, the fraction of ultra-fine grains (less than $3 \mu \mathrm{m}$ ) increases notably.

\subsection{Scanning electron microscopy}

The results of studies have demonstrated that the type of the grain boundaries is similar at low strains for both technologies: relatively coarse grains delimited by high-angle grain boundaries with misorientation angles higher than $15^{\circ}$ (HAGBs) are observed (Fig. $3 \mathrm{a}, \mathrm{b}$ ). Inside these grains a fine structure has been formed in the shape of pileups of dislocations, cells and low-angle grain boundaries (LAGBs), i. e. sub-boundaries with misorientation below $15^{\circ}$. However, the total density of the LAGBs after the experimental shear drawing is higher than after the drawing by the classical scheme ( $49 \%$ vs. $40 \%$ respectively).

Table 4. Grain size after drawing of the low-carbon steel wire.

\begin{tabular}{|c|c|c|c|c|}
\hline \multirow{2}{*}{ Diameter, mm } & \multicolumn{4}{|c|}{ Grain size, $\mu \mathrm{m}$} \\
\cline { 2 - 5 } & \multicolumn{2}{|c|}{ Classical } & \multicolumn{2}{c|}{ Experimental } \\
\cline { 2 - 5 } & Along & Across & $8.78 \pm 0.5$ & 4.50 Across \\
\cline { 2 - 5 } & $8.70 \pm 0.5$ & $5.72 \pm 0.5$ & $4.14 \pm 0.5$ & $4.5 \pm 0.5$ \\
\hline 5.0 & $9.02 \pm 0.5$ & $4.02 \pm 0.5$ & $3.28 \pm 0.5$ \\
\hline
\end{tabular}

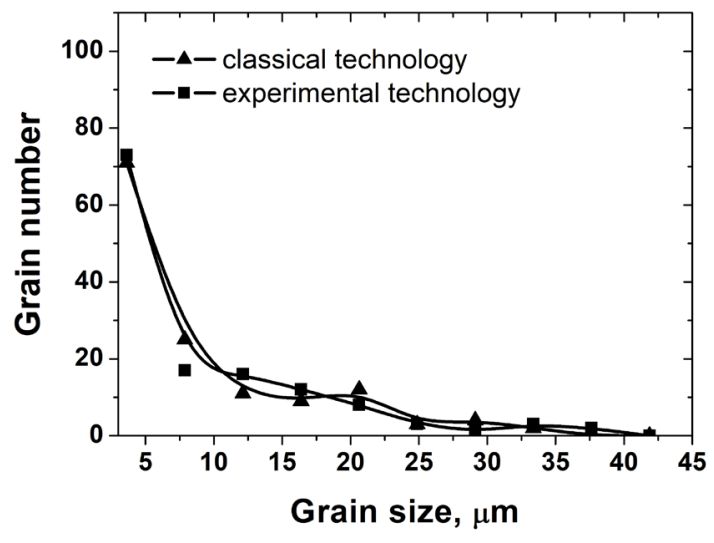

a

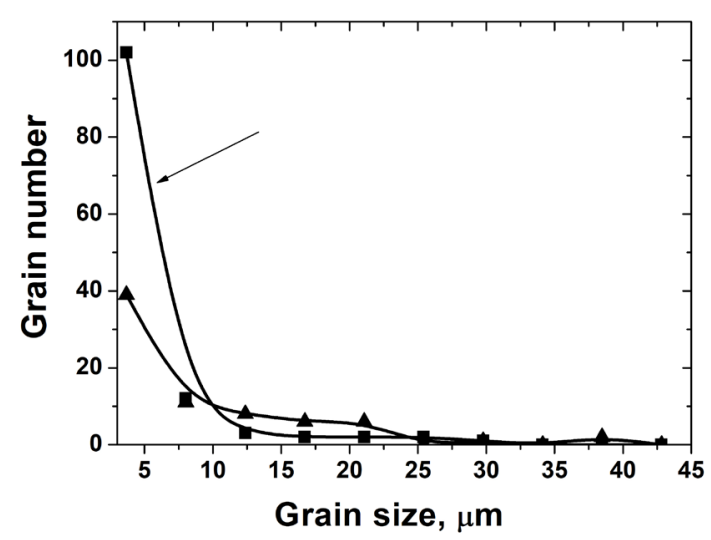

C

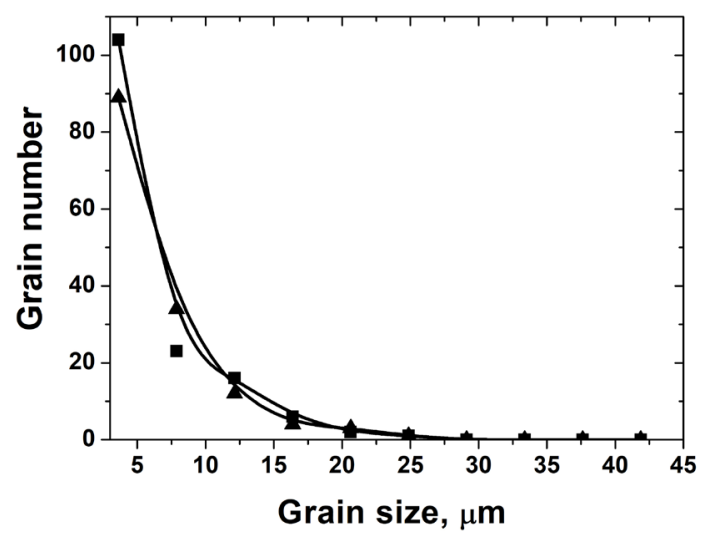

$\mathrm{b}$

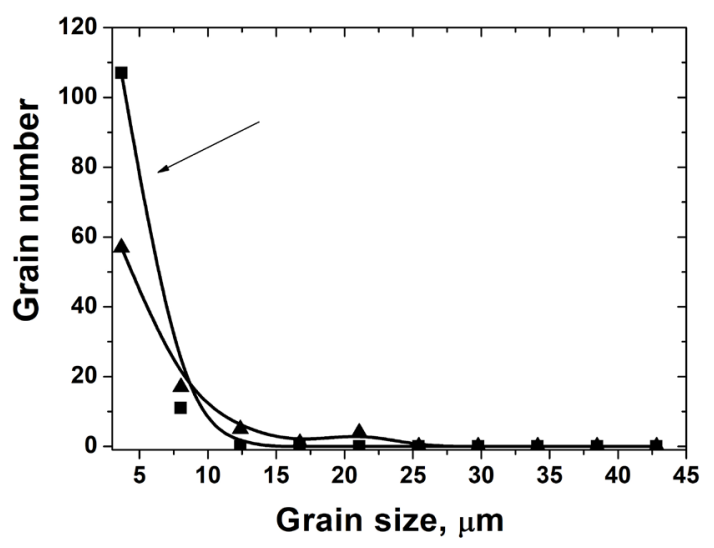

d

Fig. 2. Grain size histograms in the samples of the low-carbon steel wire. $\varnothing 5.0 \mathrm{~mm}(\mathrm{a}, \mathrm{b}) ; \varnothing 3.9 \mathrm{~mm}$ (c, d). 
At the same time, when the strain increases (Fig. 3c,d), the type of the formed boundaries changes. After the classical drawing, the dislocations are arranged in sub-boundaries. Due to this fact, areas relatively free of defects appear within the grains. After the experimental drawing, the fraction of the HAGBs grows substantially (up to 65\%) both at the cost of very small fragmented grains less than about $3 \mu \mathrm{m}$ in size and at the rate of relatively large grains that increase the grainboundary angle in the course of deformation.

Besides, EBSD allowed the analysis of grains of different types: deformed, substructural, recrystallized. The grains are classified as follows:

1. a criterion of the grain selection is established (the misorientation angle is above $15^{\circ}$, being associated with the $\mathrm{HABs}$;

2. the threshold value of misorientation is selected that corresponds to the standard instrumental error $\left(2^{\circ}\right)$;

3 . if the average value of misorientation of the points within a grain exceeds the selected threshold value, the grain is identified as a deformed one;

4. if the grain is composed of subgrains and the average value of misorientation within the subgrains does not exceed the threshold value but there is an excess between the subgrains, then the grain is a substructural one;

5. if the average misorientation within a grain does not exceed the selected threshold value, the grain is a recrystallized one.

In Figs. 4 and 5 the maps of crystallographic orientations and the grain types after different kinds of drawing are

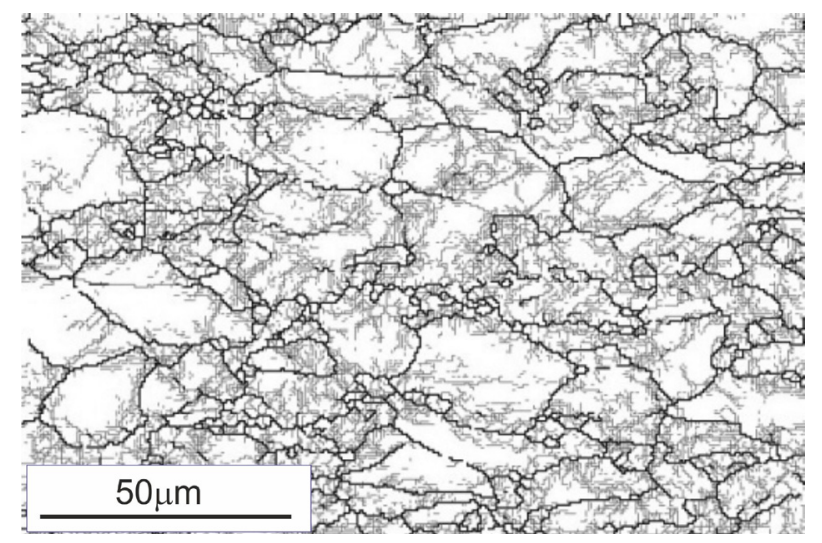

a

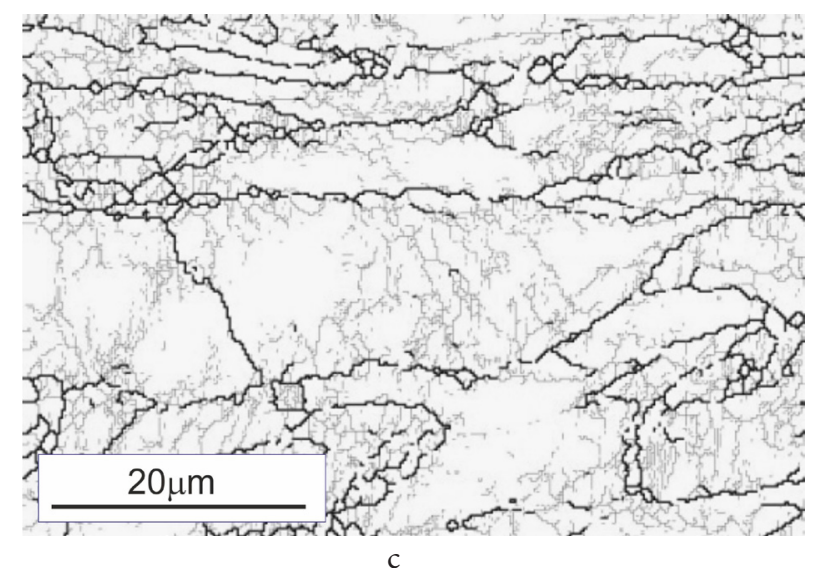

presented. The maps confirm the idea that the formed small grains (less of $3 \mu \mathrm{m}$ ) are recrystallized. A possible mechanism of formation of this type of grains is fragmentation of coarse grains [16] to the grain size down to $3 \mu \mathrm{m}$. This type of grains should demonstrate structure imperfection due to a large number of defects and related noticeable lattice distortions. However, it has been established that the change of crystallographic orientations within the grains is stepwise, not smooth due to the bending of crystallographic planes (Fig. $4 \mathrm{~d}$, shown with an arrow). In other words, the grains are structurally "ideal", the lattice inside the small grains is not distorted. This fact characterizes the case of creation of deformed structure due to the grain boundary sliding (GBS) or GBS combined with dynamic recrystallization [9]. A consequence of these processes is the change of the type of the grain boundaries from smooth to serrated and the formation of unclosed HAGBs [21].

The data presented in Fig. $5 \mathrm{c}$, d count in favour of the last statement. After the drawing with the experimental technology, the amount of the recrystallized grains increases from $2.5 \%$ to $4.8 \%$ in comparison with the classical drawing technology. An increase in the fraction of the deformed grains, moreover, is enhanced from $12.5 \%$ to $22 \%$. The presence of recrystallized grains is an evidence of occurred mechanically activated dynamic recrystallization.

At high strain, therefore, the structures formed by the classical and experimental drawing technologies differ drastically. After the experimental processing, the grains are refined more substantially. The experimental technology

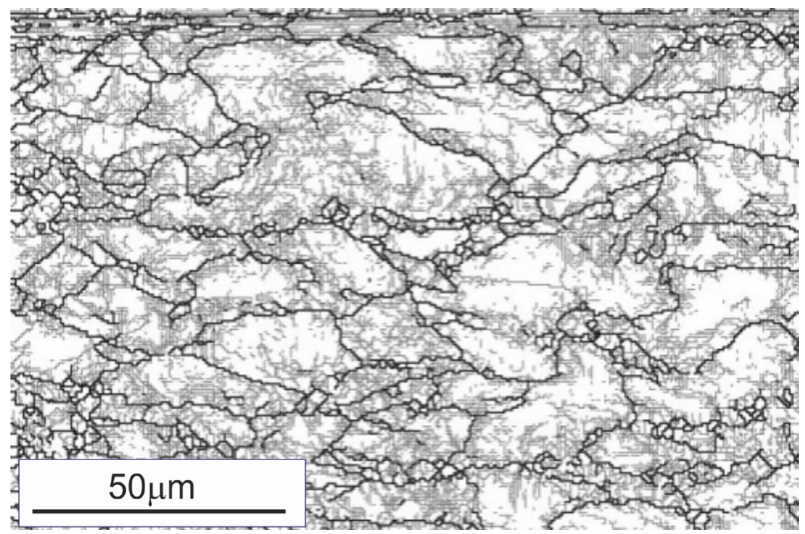

$\mathrm{b}$

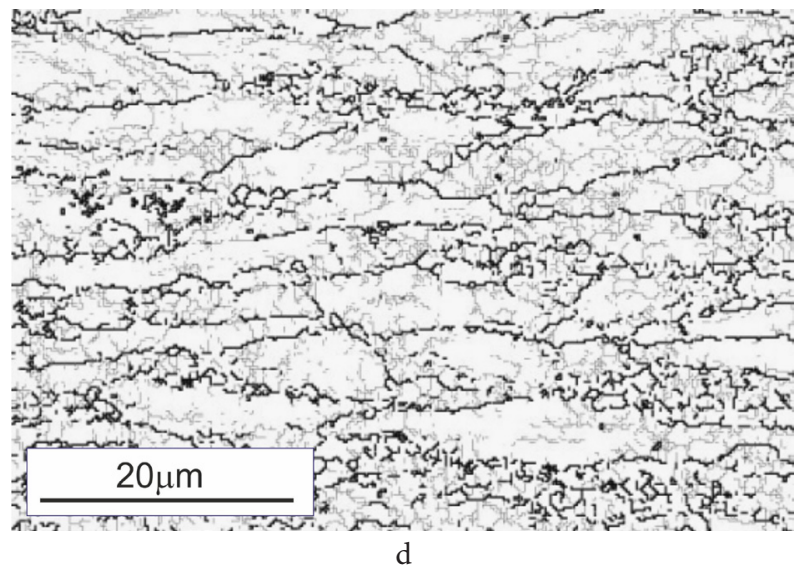

Fig. 3. Maps of the grain boundaries of low-carbon steel wire samples (longitudinal section), obtained by the classical technique (a, $c$ ) and by the experimental technique (b, d); Ø5.0 $\mathrm{mm}(\mathrm{a}, \mathrm{b}) ; \varnothing 3.9 \mathrm{~mm}$. HAGBs and LAGBs are marked black and grey respectively. 


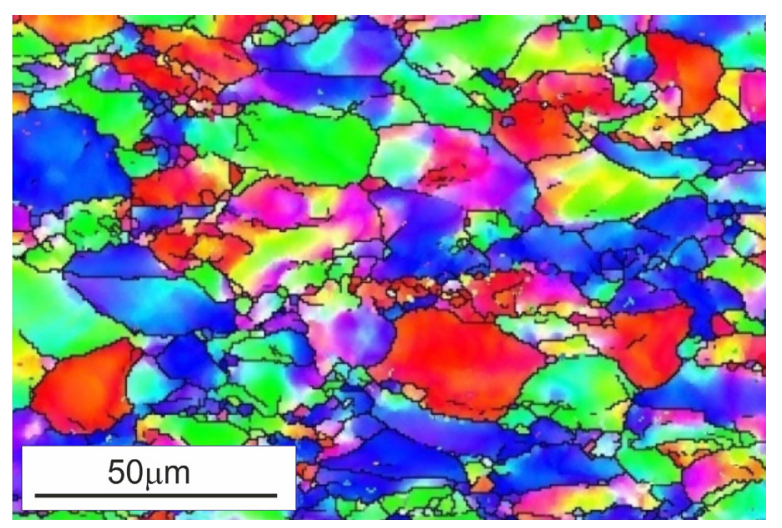

a

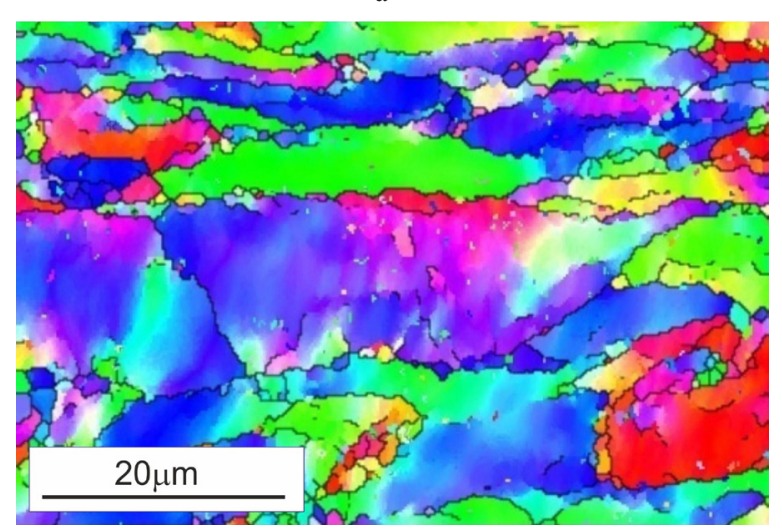

c

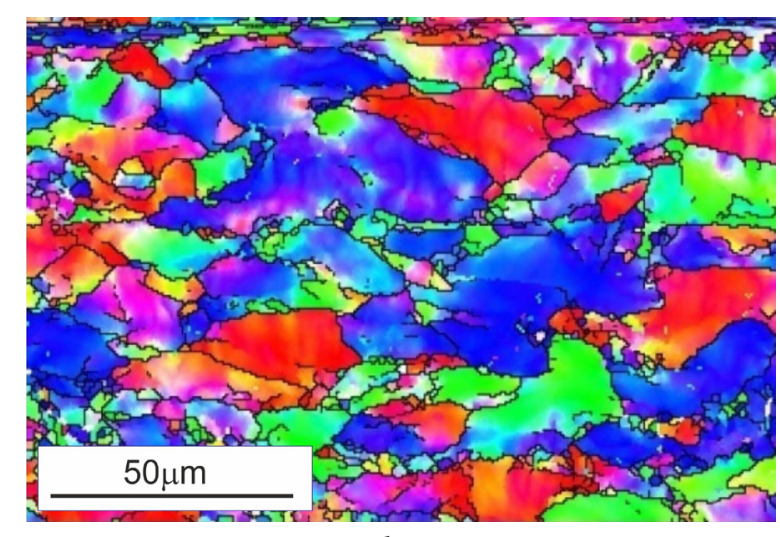

$\mathrm{b}$

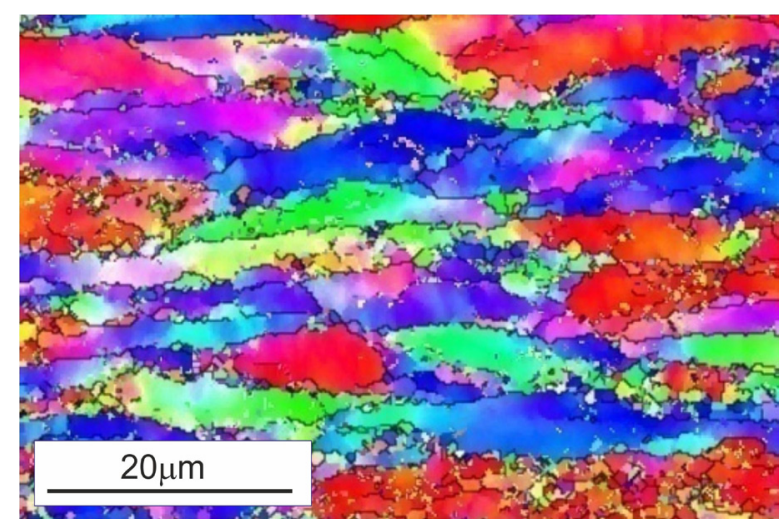

d

Fig. 4. (Color online) IPF Maps of the crystallographic orientations of low-carbon steel wire samples (longitudinal section), obtained by the classical technique (a, c) and by the experimental technique (b, d); $\varnothing 5.0 \mathrm{~mm}(\mathrm{a}, \mathrm{b}) ; \varnothing 3.9 \mathrm{~mm}(\mathrm{c}, \mathrm{d})$.

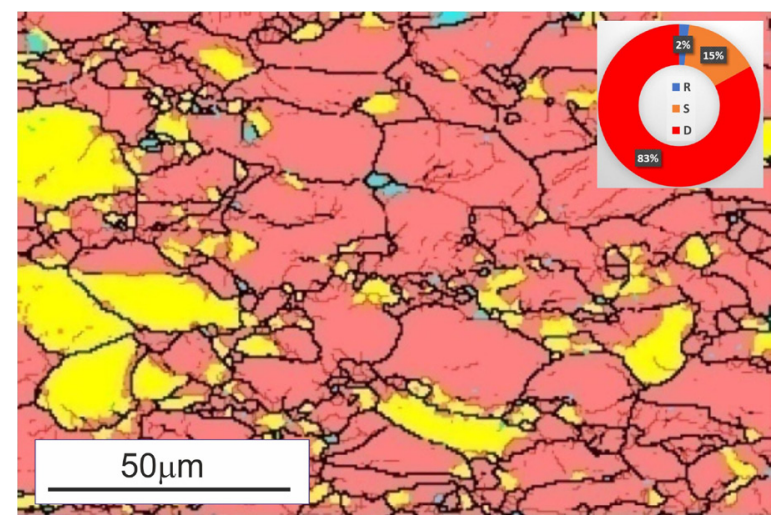

a

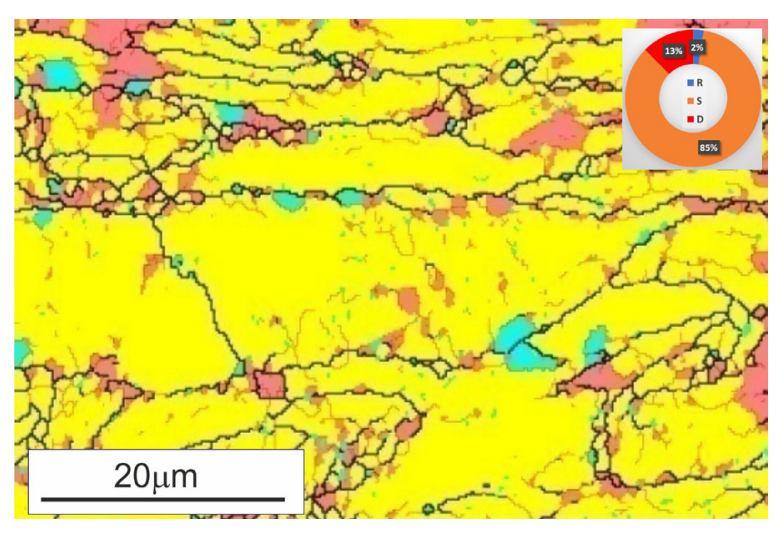

c

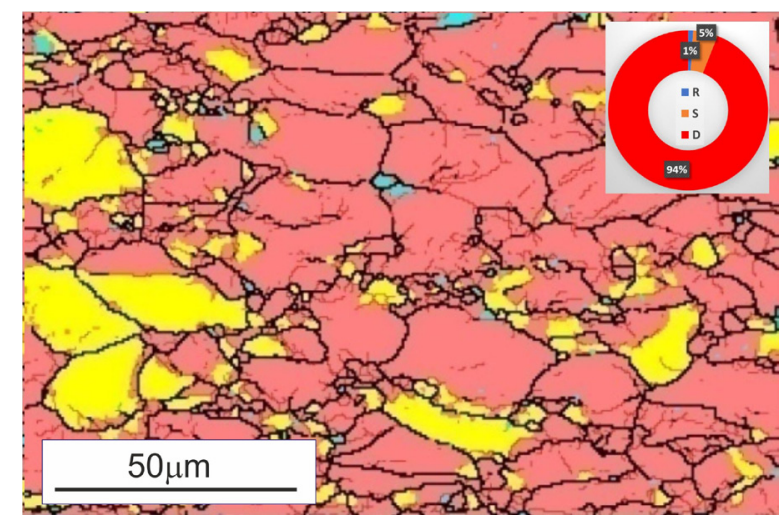

b

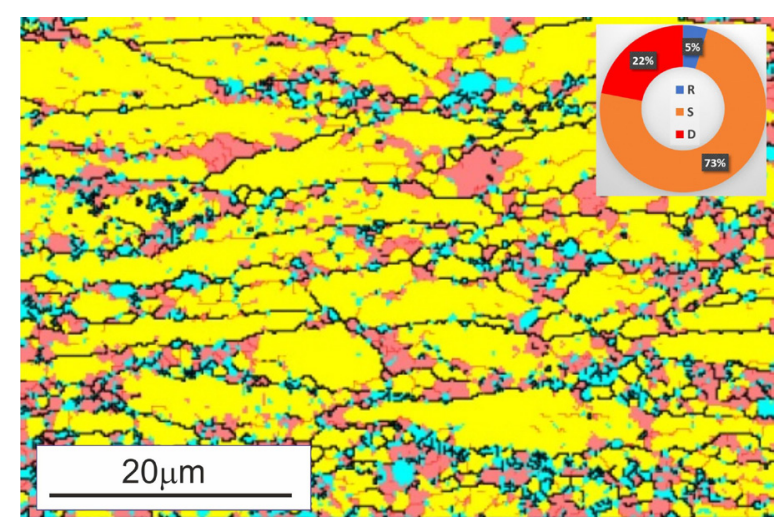

$\mathrm{d}$

Fig. 5. (Color online) Maps of the grain types in the samples of low-carbon steel wire samples (longitudinal section), obtained by the classical technique (a,c) and by the experimental technique (b, d); $\varnothing 5.0 \mathrm{~mm}(\mathrm{a}, \mathrm{b}) ; \varnothing 3.9 \mathrm{~mm}(\mathrm{c}, \mathrm{d})$. The deformed (D), substructural (S) and recrystallized $(\mathrm{R})$ grains are marked pink, yellow and blue, respectively. 
results in a noticeable increase in the fraction of small grains (less than $3 \mu \mathrm{m}$ in diameter) and a reduction in the fraction of large grains. A large amount of small grains with HAGBs is registered.

\subsection{Physical and mechanical properties}

The study of unetched specimens by optical metallography demonstrated that pores are formed when wire passes the first die with shear. These pores are healed to a large degree during subsequent drawing. This fact is confirmed by the data about the pore density (Fig. 6). The utilization of the second die with shear results in a process of density recovery up to the wire of small diameter $\varnothing 1.55$. On a whole, the density of the experimental drawn samples is substantially larger and this provides high drawing ability without annealing.

When using the experimental technology, an important specific feature is the fact that the hardness exceeds approximately by $30 \mathrm{HV}$ that after the classical drawing both in the longitudinal and the transversal sections (starting from $\varnothing 2.42$ ). An increase in hardness after the experimental drawing is associated with the appearance of a large amount of small grains with high-angle boundaries. In the author's opinion, this kind of the structural modification is a consequence of the development of dynamic recrystallization against the background of the persisting grain fragmentation during drawing. The nuclei of new grains appear and start growing at the boundaries of the deformed primary grains. When the size of new grains increases gradually, they become involved in the deformation process. As a result, their equiaxed shape becomes elongated and the lattice becomes distorted. Thus, the progressing dynamic recrystallization is associated with an increment of the hardness, not a decrease.

The enhanced density can be explained by a healing of pores and cavities. This fact is confirmed by the optical metallography. An explanation could be related to the changes of the metal flow direction when the wire passes the conventional dies after a die with shear.

An advanced characterization of the studied samples is planned by using neutron beam techniques, which has been already adopted to analyse wire samples made of lowalloyed quality structural steel Grade 08G2S GOST 1050 with

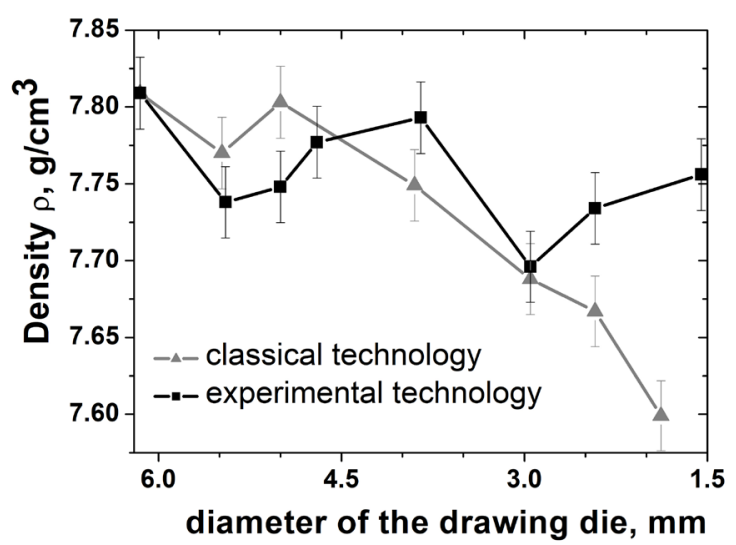

Fig. 6. Density of the wire from the low-carbon steel produced by different technologies.

accumulated shear deformation [22,12]. Such additional investigation would complement the information achieved from the other characterization methodologies, providing substantial data helping to evaluate the effect of shear deformation:

- on residual stresses (by using neutron diffraction), to help develop a low-carbon wire drawing technology with needed manufacturability and efficiency;

- on nano/micro-structure (by using small angle neutron scattering), studying the morphology of grains and monitoring anisotropy and other key parameters of eventual nanocracks, nanopores and other nanosized defects, responsible for mechanical properties.

\section{Conclusions}

The feasibility of drawing with shear for grain boundary engineering in low-carbon steel wire was examined. As compared to conventional drawing technology, the new approach was shown to result in enhanced grain refinement, reduction of the structural anisotropy and thus it imparted additional material strengthening. All of these benefits were attributed to a specific shear deformation impact.

At a high degree of deformation, grain reduction is stronger during the experimental drawing processing. The

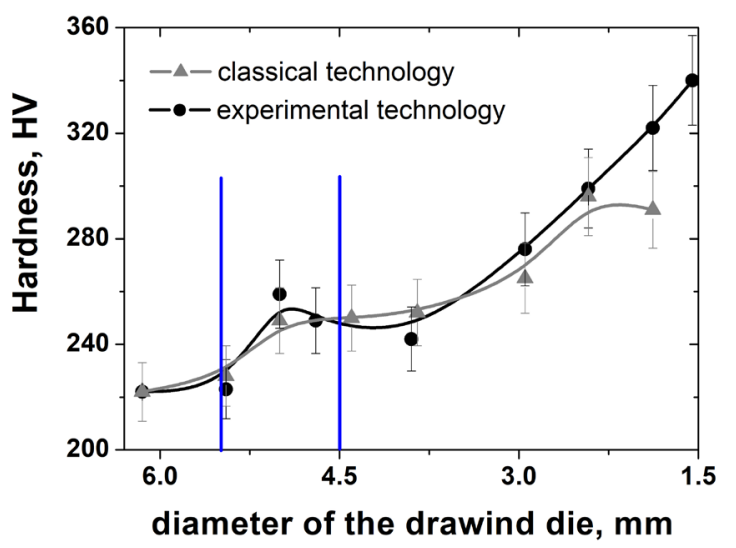

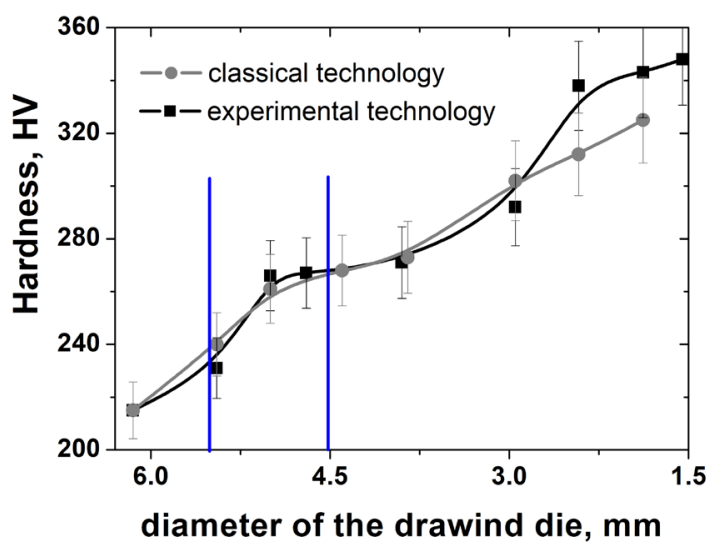

b

Fig. 7. Hardness of the wire from low-carbon steel produced by the classical and the experimental technologies: cross-section (a), longitudinal section (b). 
experimental drawing technology results in an extensive increase of the fraction of small grains and a decrease in the fraction of large grains. Predominantly small grains with high-angle grain boundaries is registered on the boundary. Such behaviour is explained by progress in competing processes of large grain fragmentation and dynamic recrystallization. The result is the change of the character of the grain boundaries from smooth to serrated ones and the formation of unclosed high-angle grain boundaries. Besides, it has been demonstrated that a certain part of small grains provides grain boundary sliding.

The application of dies with shear that makes the metal flow to change the direction leads to a reduction of the structural anisotropy and pores healing.

The comparative analysis of the hardness tests has demonstrated increases with shear deformation accumulation. Opposite to classical drawing linear growth of the hardness is changed to stepwise. Linear increase of the hardness is related to a decrease in the grain size and formed an enhanced density of low-angle boundaries and dislocations. Stepwise behaviour is a consequence of the development of dynamic recrystallization against the background of the persisting grain fragmentation during drawing.

Acknowledgements. The work was performed with the support of the economic contracts project \#13-13 "Wire drawing technology to improve ductility without the use of the heat treatment". The authors are grateful to Dr.S. Mironov, Dr. V. Burkhovetskiy, PhD-student A. Maksakova, for their help in the experiment. Dr. M. E. Heaton (ANT, Advanced Nano Technology, Nandor Rd, Park West business park, Dublin) for help in the preparation of this manuscript

\section{References}

1. R.Z. Valiev. Met. Mater. Int. 7, 413 (2001). Crossref

2. U. Mayo, N. Isasti, J.M. Rodriguez-Ibabe, P. Uranga. Mater. Sci. Eng. A. 792, 139800 (2020). $\underline{\text { Crossref }}$

3. L. Lobanov, V. Poznyakov, V. Pivtorak, O. Mikhodui, V. Orlovs'Kyi. Mater. Sci. 45, 768 (2009). Crossref

4. O. Berdnikova, V. Pozniakov, A. Bernatskyi, T. Alekseienko,
V. Sydorets. In: Procedia Struct. Integr. Vol. 16 (2019) pp. 89-96. Crossref

5. O. Berdnikova, V. Sydorets, T. Alekseienko. Appl. Mech. Mater. 682, 240 (2014). Crossref

6. T. Bajor, A. Kulakowska, H. Dyja. Materials (Basel). 13 (5), 1114 (2020). Crossref

7. H.S. Kim, Y. Estrin, M. B. Bush. Acta Mater. 48, 493 (2000). Crossref

8. Y. Beygelzimer. Mech. Mater. 37, 753 (2005). Crossref

9. O.A. Kaübyshev, F.Z. Utyashev. Superplasticity: microstructural refinement and superplastic roll forming. Futurepast Incorporated (2005).

10. L. Priester. Grain Boundaries: From Theory to Engineering. Springer, New York (2012). Crossref

11. E. Pashinskaya, A. Zavdoveev, S. Mironov, V. Varyukhin, A. Maksakova. Int. J. Mater. Res. 107, 239 (2016). Crossref

12. A. Zavdoveev, A. Len, E. Pashinska. Met. Mater. Int. (2020). Crossref

13. Z.A. Samoilenko, N.N. Ivakhnenko, E.I. Pushenko, V.N. Varyukhin, E. G. Pashinskaya, V.M. Tkachenko, A. V. Zavdoveev. Tech. Phys. 64, 187 (2019). Crossref

14. A. Vinogradov. Adv. Eng. Mater. 17, 1710 (2015). Crossref 15. Y. Estrin, A. Vinogradov. Acta Mater. 61, 782 (2013). Crossref

16. E. Pashinska, V. Varyukhin, S. Dobatkin, A. Zavdoveev. Emerg. Mater. Res. 2, 138 (2013) . Crossref

17. A. Zavdoveev, E. Pashinska, S. Dobatkin, V. Varyukhin, N.N. Belousov, A. Maksakova, F. Glazunov. Emerg. Mater. Res. 4, 89 (2015). Crossref

18. Y. Beygelzimer, R. Kulagin, Y. Estrin, L.S. Toth, H.S. Kim, M. I. Latypov. Adv.Eng. Mater. 19, 1600873 (2017). Crossref

19. A. Zavdoveev, T. Baudin, E. Pashinska, M. Skoryk. Emerg. Mater. Res. 6, 260 (2017). $\underline{\text { Crossref }}$

20. E.G. Pashinskaya, A.V. Zavdoveev, L.S. Metlov, Y.I. Nepochatikh, A.A. Maksakova, V.M. Tkachenko. Mater. Phys. Mech. 24, 163 (2015). (in Russian)

21. W. Gu, J. Li. Int. J. Miner. Metall. Mater. 22, 721 (2015). Crossref

22. M. Rogante, P. Mikula, P. Strunz, A. Zavdoveev. Proc. 7th Int. Conf. "Mechanical Technologies and Structural Materials” MTMS2017. Split, Croatia (2017) p. 111. 